University of Nebraska - Lincoln

DigitalCommons@University of Nebraska - Lincoln

\title{
Sandhill Crane Abundance and Nesting Ecology at Grays Lake, Idaho
}

Jane Austin

United States Geological Survey, jaustin@usgs.gov

Adonia Henry

United States Geological Survey

I. Joseph Hall

United States Geological Survey

Follow this and additional works at: https://digitalcommons.unl.edu/usgsnpwrc

Part of the Other International and Area Studies Commons

Austin, Jane; Henry, Adonia; and Hall, I. Joseph, "Sandhill Crane Abundance and Nesting Ecology at Grays Lake, Idaho" (2007). USGS Northern Prairie Wildlife Research Center. 7.

https://digitalcommons.unl.edu/usgsnpwrc/7

This Article is brought to you for free and open access by the US Geological Survey at DigitalCommons@University of Nebraska - Lincoln. It has been accepted for inclusion in USGS Northern Prairie Wildlife Research Center by an authorized administrator of DigitalCommons@University of Nebraska - Lincoln. 


\title{
Sandhill Crane Abundance and Nesting Ecology at Grays Lake, Idaho
}

\author{
JANE E. AUSTIN, ${ }^{\mathbf{1}}$ United States Geological Survey, Northern Prairie Wildlife Research Center, 8711 37th Street S.E., Jamestown, ND 58401, USA \\ ADONIA R. HENRY, ${ }^{2}$ Montana Cooperative Wildlife Research Unit, United States Geological Survey, University of Montana, \\ Missoula, MT 59812, USA \\ I. JOSEPH BALL, ${ }^{3}$ Montana Cooperative Wildife Research Unit, United States Geological Survey, University of Montana, Missoula, MT 59812, USA
}

\begin{abstract}
We examined population size and factors influencing nest survival of greater sandhill cranes (Grus canadensis tabida) at Grays Lake National Wildlife Refuge, Idaho, USA, during 1997-2000. Average local population of cranes from late April to early May, 1998-2000, was 735 cranes, 34\% higher than that reported for May 1970-1971. We estimated 228 ( $\mathrm{SE}=30)$ nests in the basin core (excluding renests), $14 \%$ higher than a 1971 estimate. Apparent nest success in our study $(\bar{x}=60 \%, n=519$ nests) was lower than reported for Grays Lake 30-50 years earlier. Daily survival rates (DSRs) of all nests averaged $0.9707(41.2 \%)$. The best model explaining nest survival included year and water depth and their interaction. Nest survival was highest (DSR $=0.9827)$ in 1998 compared with other years $(0.9698-0.9707)$. Nest survival changed little relative to water depth in 1998, when flooding was extensive and alternative prey (microtines) irrupted, but declined markedly with lower water levels in 2000, the driest year studied. Hypotheses relating nest survival to vegetation height, land use (idle, summer grazing, fall grazing), and date were not supported. In a before-after-control-impact design using 12 experimental fields, nest survival differed among years but not among management treatments (idle, fall graze, fall burn, and summer-graze-idle rotation), nor was there an interaction between year and treatments. However, DSRs in fall-burn fields declined from 0.9781 in 1997-1998 to 0.9503 in 1999-2000 (posttreatment). Changes in the predator community have likely contributed to declines in nest success since the 1950s and 1970s. Our results did not support earlier concerns about effects of habitat management practices on crane productivity. Nest survival could best be enhanced by managing spring water levels. Managers should continue censuses during late April to evaluate long-term relationships to habitat conditions and management. (JOURNAL OF WILDLIFE MANAGEMENT 71(4):1067-1079; 2007)
\end{abstract}

DOI: $10.2193 / 2005-705$

KEY WORDS Grays Lake, Grus canadensis tabida, habitat management, Idaho, nesting ecology, population, sandhill crane.

The Rocky Mountain Population (RMP) of greater sandhill cranes (Grus canadensis tabida) recovered from low numbers in the early 1900 s to $>18,000$ cranes by 2001 (Sharp et al. 2002). Indices of the fall population indicate that the size of the RMP has been relatively stable since 1995 (Sharp et al. 2002), but there is concern that recruitment and breeding populations may have declined (Drewien et al. 1995). Percentage of juveniles in the RMP in autumn averaged $7.7 \%$ during 1972-2001 (Sharp et al. 2002), the lowest production rate recorded for any hunted avian species in North America (Drewien et al. 1995). Although annual variation in production has been attributed to weather, availability of food and water, and predation on the breeding ground (Drewien et al. 1995), little published data are available to assess the influence of such factors on nest or chick survival.

Grays Lake, a large, shallow montane wetland in southeastern Idaho, USA, has historically supported the largest and densest breeding concentrations of greater sandhill cranes in the RMP (Drewien and Bizeau 1974). Drewien (1973) estimated 549 cranes were in the Grays Lake basin during May 1970-1971. Two earlier studies at Grays Lake reported nest success rates for sandhill cranes (Steel 1952, Drewien 1973). These studies provided a valuable oppor-

${ }^{1}$ E-mail: jane_austin@usgs.gov

2 Present address: United States Fish and Wildlife Service, Pacific Islands Fish and Wildlife Office, 300 Ala Moana Boulevard, Room 3-122, Honolulu, HI 96850, USA

${ }^{3}$ Present address: 35755 Leon Road, Charlo, MT 59824, USA tunity to examine changes in sandhill crane abundance and nest survival rates over $30-50$ years.

Much of the wet meadow habitat important to nesting sandhill cranes in the Grays Lake Valley lies within the Grays Lake National Wildlife Refuge (GLNWR). Concerns about habitat management practices on refuge lands in the 1980s (Coleman et al. 1990) and reported decline of the local crane population during the 1990s (Drewien 1997) led us to investigate the population and nesting ecology of sandhill cranes during 1997-2000 at Grays Lake on both refuge and adjacent private lands. The objectives of this study were to 1) compare numbers of sandhill cranes in the Grays Lake Valley during the breeding season with historical data, 2) compare numbers of crane nests in the valley with historic data, and 3) evaluate factors affecting survival of crane nests, including effects of habitat management practices. Consistent with previous studies of nesting cranes (Littlefield and Ryder 1968, Stern et al. 1987, Littlefield and Paullin 1990, Smith and Smith 1992, Urbanek and Bookhout 1992, Littlefield et al. 2001), we hypothesized that nest success would be higher with greater water depth and vegetation height at the nest and that land use practices that reduced vegetative cover would reduce nest success. We also hypothesized that julian date would influence nest survival, as has been reported for ducks (Flint and Grand 1996, Grand and Flint 1997, Traylor et al. 2004). We discuss changes in crane abundance and nest survival relative to habitat management and environmental changes in the valley. 


\section{STUDY AREA}

Grays Lake lies in a high elevation $(1,946 \mathrm{~m})$ valley within the Caribou Range of the Rocky Mountains in southeast Idaho, at the western edge of the Greater Yellowstone Ecosystem (Fig. 1; Clark et al. 1999). At the heart of the valley was a 5,260-ha shallow, montane wetland, vegetated primarily by bulrush (Schoenoplectus spp.) and cattail (Typha spp.). Wet meadows surrounding the bulrush-cattail core were a mosaic of seasonally (1,264 ha) and temporarily (914 ha) flooded wetlands dominated by Baltic rush (Juncus balticus), tufted hairgrass (Deschampsia caespitosa), Kentucky bluegrass (Poa pratensis), brome (Bromus spp.), mat muhly (Mublenbergia richardsonis), spikerush (Eleocharis spp.), and sedges (Carex spp.). The valley received snow accumulations of $>200 \mathrm{~cm}$ annually and had a total annual precipitation of approximately $54 \mathrm{~cm}$ (National Oceanographic and Atmospheric Administration 2002).

Water levels of Grays Lake were affected primarily by spring runoff, precipitation, evaporation-transpiration balance, and water-level management at 2 outflows that are controlled by the United States Bureau of Indian Affairs. Lake levels during spring were usually high enough to flood the surrounding meadows but were typically drawn down to a standard level by late June to supply water for irrigation elsewhere, leaving only the cattail-bulrush and other deepwetland communities with standing water. Spring water

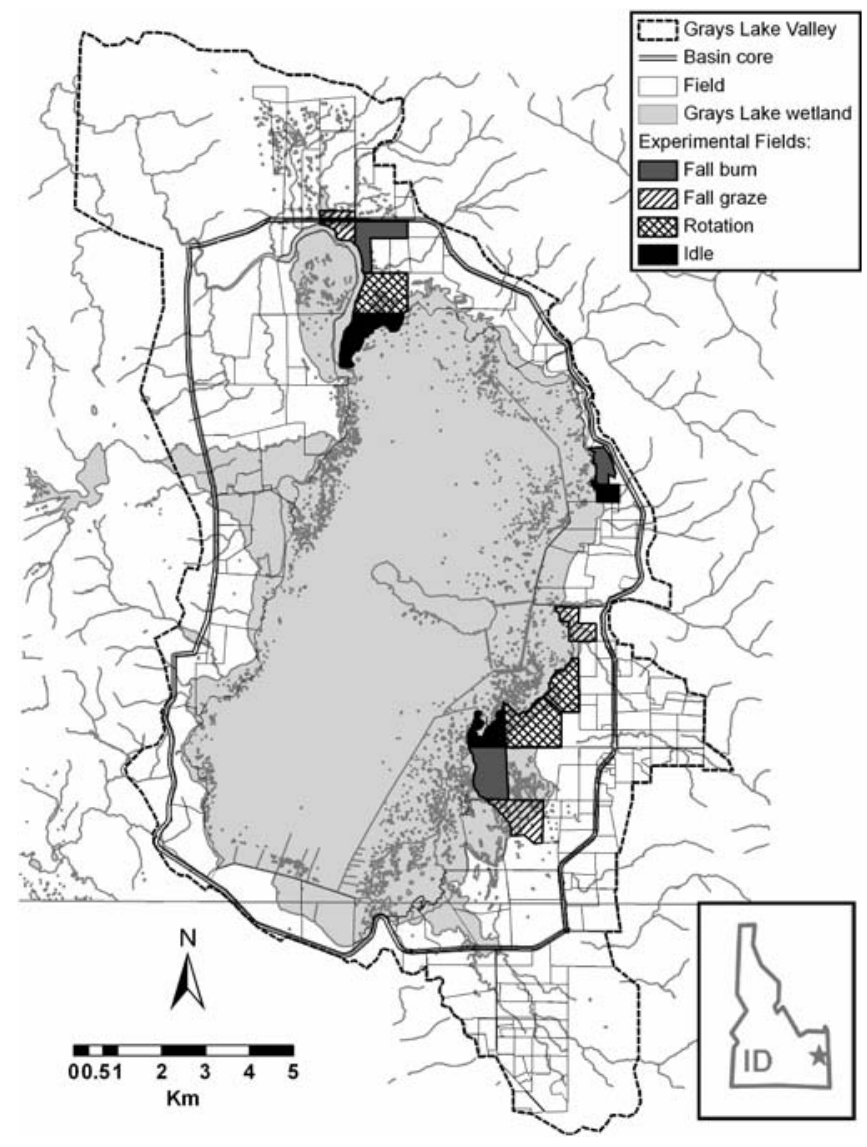

Figure 1. Grays Lake Valley, basin core, and boundaries of experimental and nonexperimental fields at Grays Lake, Idaho, USA. levels during our study, as measured on the south end of the basin, were substantially above the long-term (1979-2000) median in 1997, above the median in 1998 and 1999, and near median levels in 2000 (Fig. 2).

Most of the interior marsh, as well as large areas of wet meadows, was contained within GLNWR. Based on data from the National Wetland Inventory, fields under United States Fish and Wildlife Service (USFWS) control that border the interior cattail-bulrush marsh were dominated by seasonally flooded $(45 \%)$, temporarily flooded $(23 \%)$, and semipermanently flooded wetland $(21 \%)$, with small amounts of upland $(11 \%)$ and permanently flooded wetland $(<1 \%)$. These wet meadow and upland areas were managed by USFWS using summer and fall grazing, fall burning, and haying; some fields were idled for $\geq 1$ year. Ranching (cattle, sheep, and hay production) has been the predominant land use in the valley by private landowners since the late 1800s. Currently, the cattle grazing of upland and wetland areas occurs from June through early November.

At the beginning of our study, we delineated fields throughout the basin, on both public and private lands, following fence lines and natural boundaries (Fig. 1). We incorporated information on field boundaries, size, and ownership into a Geographic Information System (GIS). We defined the basin core as the area lying within the perimeter roads around the main wetland area (Fig. 1).

\section{METHODS}

\section{Populations}

We conducted censuses in the Grays Lake Valley during spring of 1998 to 2000 to 1) document the size of the sandhill crane population during the breeding season, 2) estimate the proportion of breeding cranes, and 3) provide a basis for comparison to previous estimates of nest abundance. We defined the local population as adult crane pairs breeding within the Grays Lake Valley and nonbreeding cranes present in the same area during spring, summer, and early fall before arrival of migrants. We conducted censuses twice a week from approximately 15 April to 10 May. We recorded the number of cranes observed, status (single, pair [ 2 cranes $<5 \mathrm{~m}$ apart], group [ $\geq 3$ cranes $<5 \mathrm{~m}$ apart]), and group size by field. Because we surveyed a slightly smaller area in 1998 than in subsequent years, we calculated a projected total for 1998 assuming that the distribution of cranes was similar in 1998 and 1999. Using binoculars and spotting scopes, 2-3 observers conducted censuses by truck or all-terrain vehicle (ATV) from roads and trails to locate and count cranes. Censuses began 30 minutes after sunrise and ended by 1300 hours to minimize double-counting of cranes moving from foraging to roosting areas. We did not conduct censuses when precipitation or fog reduced visibility. We established 3 routes and appropriate observation points so observers could view all areas in the valley, including areas obstructed by hills or tall vegetation, from elevated sites and various angles. We established endpoints of route segments in areas typically having low crane densities. We thoroughly scanned for cranes in all fields 


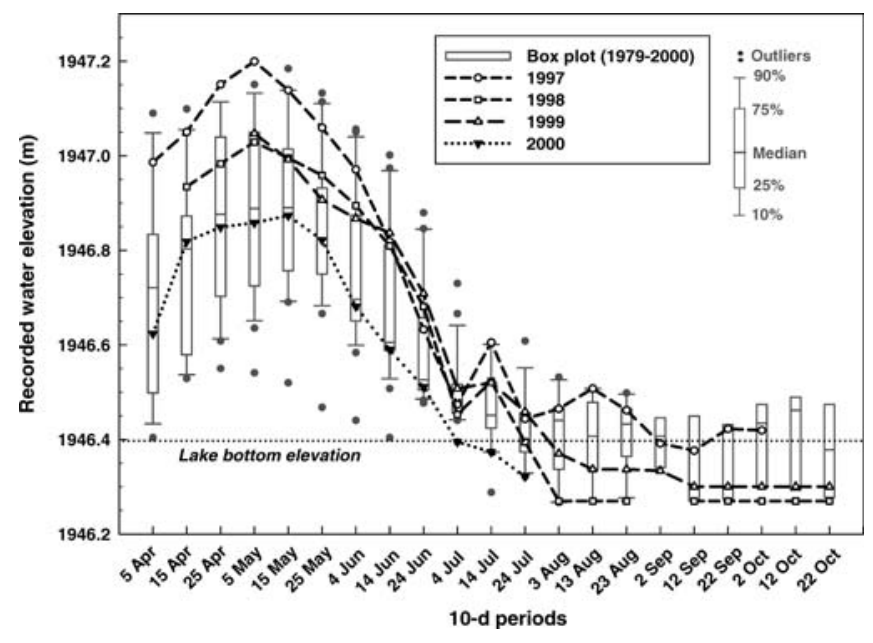

Figure 2. Water levels recorded during 1997-2000 at Beavertail Point, Grays Lake, Idaho, USA, relative to long-term (1979-2000) historical trends (box plots).

within the Grays Lake Valley, interior marsh, dikes, and adjacent upland habitats. We did not count cranes in flight unless we could determine their origin and verify that they had not been counted previously. Observers performed censuses along the same survey route throughout the field season because familiarity with the route and locations of fields increased accuracy and efficiency. To reduce any potential bias related to starting time, we alternated starting and ending points of each route (i.e., we initiated a route at its northernmost point for one census and the southernmost point for the next census).

\section{Nesting Ecology}

We conducted nest searching in 1997-1999 from 1 May to 15 June in all fields; in 2000, nest searching began on 25 April. We located crane nests primarily by foot or canoe searches and remote observation using binoculars or spotting scopes; on some refuge fields, we also used chain-drags and ATVs. We recorded information on nest status, nest-site vegetation, water depth, and nest fate following procedures established by Klett et al. (1986). We checked nests periodically (median interval $=8 \mathrm{~d}$ ) until all nests were terminated. Because cranes hatch asynchronously, we continued nest visits until we knew the fate of both eggs in clutches with $>1 \mathrm{egg}$. We considered a nest successful if $\geq 1$ egg hatched, as determined by shell fragments in the nest platform or detached membranes $\leq 5 \mathrm{~m}$ of the nest platform (Rearden 1951; C. D. Littlefield, California Department of Fish and Game, unpublished report). We considered nests with cold, uncovered, intact eggs and with no crane present abandoned; we later rechecked nest status to verify abandonment. If a crane was present, but the incubation stage of the eggs had not progressed in successive visits, we considered the eggs addled or infertile.

Where possible, we observed nests from a distance with binoculars or spotting scopes to reduce disturbance by direct visits. If we observed a crane sitting on the nest platform, we considered the nest active. If no crane was present, we visited the nest directly to determine whether it was terminated or still active (eggs present and warm and incubation stage had progressed). To further minimize disturbance, we approached crane nests on foot. We kept all ATV activity $>30 \mathrm{~m}$ from nests. For each nest, we plotted its location on an aerial photograph copy of the field, recorded the Universal Transverse Mercator coordinates to the nearest $10 \mathrm{~m}$ using a Global Positioning System (GPS) receiver, and marked them using willow stakes labeled with the nest number to facilitate relocation. In the first 2 years, we tied colored flagging to the willows; however, concerns about detection of marked nests by American crows (Corvus brachyrhynchos) and common ravens (Corvus corax; Greenwood and Sargeant 1995) caused us to abandon that practice in 1999 and 2000.

At each nest visit, we recorded number of eggs, status, incubation stage, and vegetation height. We determined incubation stage by flotation (Westerkov 1950; C. D. Littlefield, unpublished report); 6 incubation stages each spanned 3-8 days. For direct visits to the nest, we recorded nest status as egg laying, incubating, hatched, destroyed, or infertile; for remote visits, we recorded nests as active or not active. We made ocular estimates of height of residual and new vegetation above the water (or soil surface if the nest was on dry ground) in each cardinal direction within a 3-m radius of the nest, then categorized average vegetation height as $0-10 \mathrm{~cm}, 10-30 \mathrm{~cm}, 30-60 \mathrm{~cm}, 60-100 \mathrm{~cm}$, or $>100 \mathrm{~cm}$. We measured water depth in each cardinal direction $1 \mathrm{~m}$ from the nest edge and recorded the average to the nearest $\mathrm{cm}$. During the first visit to a nest, we also classified the habitat within 3-4 $\mathrm{m}$ of the nest based on the predominant plant community: 1) upland (graminoids and forbs), 2) wet meadow (intermittently or temporarily flooded habitat), 3) Baltic rush-spikerush (hereafter Baltic rush), 4) robust sedge (hereafter sedge), 5) sedge-cattailbulrush, 6) cattail-bulrush, 7) overwater (located in open water within cattail-bulrush marsh), 8) willow (Salix spp.), or 9) other. We classified land-use practices of each field as 1 of 5 categories (idle, fall graze, fall burn, summer graze, and hay) based on surveys conducted by the USFWS, management records at GLNWR, and discussion with refuge staff and private landowners. Land-use categories refer to the land-use practice occurring in a field during the growing season before that nesting season.

We calculated estimated nest initiation dates and hatch dates based on incubation stage at the first nest visit, assuming a 30-day incubation period (Drewien 1973, Ellis et al. 1996). If the nest was still active when the estimated hatch date indicated it should have already hatched, we corrected age of the eggs at the first visit by back-calculating age from the actual hatch date. Most apparent errors in determining incubation stage were $\leq 4$ days, which is within the error range of the flotation method.

Because cranes are indeterminate layers capable of renesting (Mirande et al. 1996), we estimated incidence of renesting following Drewien (1973), with several modifications. Drewien (1973) found that distance between the 
initial nest and known renest was $\leq 351 \mathrm{~m}(\bar{x}=148 \mathrm{~m} ; n=7$ nests), the interval between failure of the first nest attempt and initiation of renest (renesting interval) was 15 days $(n=$ 1 nest), and cranes only renested if their nests were destroyed in the first half of incubation (4 of 7 pairs with nests destroyed before mid-incubation renested). We desired a liberal estimate of renesting, thereby a conservative estimate of nest abundance. Hence, we assumed that nests destroyed at any stage of incubation could be followed by a renest located $\leq 350 \mathrm{~m}$ of the first nest. We carefully reviewed records of nest failures to assess nest termination date, nest initiation date, and nest locations (obtained by GPS) to find nests that might be renests. Our decision to liberalize our estimate of renesting by extending renesting interval and incubation stage relative to Drewien's findings is supported by data from captive cranes (Gee 1983).

We selected 12 fields controlled by USFWS for an experimental study of the effects of habitat management practices on nesting activity and nest survival using a beforeafter-control-impact (BACI) design. We refer to these 12 fields as experimental fields and to other fields (other federal and state lands, private property) as nonexperimental fields. We selected the 12 experimental fields from 22 fields owned by the USFWS and bordering the interior deep marsh. The gradient of plant communities within each field typically spanned from dry upland to semipermanently flooded wetland communities and extended approximately 25-50 $m$ into the interior deep marsh, abutting stands of tall emergents (cattail or bulrush) or open water. We randomly assigned the fields to 1 of 4 treatment regimes, with 3 replicates for each treatment regime. Treatment regimes consisted of 1) continuous idle (no manipulation; our control); 2) fall grazing of moderate intensity (2.0-3.0 animal unit months [AUMs]/ha); 3) prescribed fall burning followed by 2 years of idle, and 4) rotation of summer grazing (2.0-3.0 AUMs/ha) followed by 2 years of idle (hereafter rotation). These treatments were similar to those applied to other USFWS fields and are part of normal refuge management activities. In 1996, all 12 fields were left idle to allow their vegetation stature to become more similar before the study began, and they remained idle during 1997 and 1998, the first 2 years of data collection. Three fields were summer grazed during July-September 1998 and idled during 1999, and 3 fields were fall-grazed during September-October 1998 and 1999. Three fields were burned in October 1998 and idled during 1999. The control fields received no treatments during 1997-1999. This BACI design allowed us to examine differences among management practices and between pre- and postapplication periods.

We systematically searched all experimental fields for crane nests every year during 1997-2000. The number of nonexperimental fields searched varied from year to year because of variation in access to private fields, spring weather conditions, and logistics. Fields ranged in size from 21 ha to 121 ha $(\bar{x}=63 \mathrm{ha})$ for the 12 experimental fields and from 1 ha to 267 ha $(\bar{x}=55$ ha, $n=125)$ for nonexperimental fields searched for crane nests. Fields typically included a range of habitat types reflecting their locations around the interior marsh but varied in number and proportions of different habitat types they contained.

Data analysis. - We calculated apparent nest success rates $(100 \times$ no. nests with $\geq 1 \mathrm{egg}$ hatched/total no. nests with known fates) to compare with historical data (Steel 1952, Drewien 1973). For all nest success and survival estimates and analyses, we excluded nests found already hatched or destroyed, nests abandoned or destroyed because of investigator disturbance, and nests with infertile or addled eggs. We used SAS Version 8.1 or 9.1 (SAS Institute, Cary, NC; SAS Institute 2002) for all analyses.

We used logistic-exposure regression methods (Shaffer 2004) to develop nest survival models and calculate nest survival. This approach is based on a generalized linear model that allows for varying visitation intervals and does not require assumptions about when nest losses occur. Because survival ( 0 or 1 ) is determined for each interval (i.e., days between visits to the nest), it can be related to continuous or categorical covariates specific to that time interval, such as water depth. Each interval becomes an observation in the analysis. In developing the exploratory models, we considered factors of biological relevance, based on information from other studies of nesting sandhill cranes and expert advice (J. E. Austin, United States Geological Survey, unpublished report). We also were interested in the potential effects of water levels, land use, and vegetation structure, which can be influenced by management actions. Specifically, we selected 5 factors that were likely to influence nest survival: water depth at the nest, vegetation height, land use (i.e. habitat management), date, and year. Three parameters varied with nest survival interval (water depth, vegetation ht, and date), whereas land use varied with nest and year. We evaluated a candidate set of 15 models based on a combination of these factors that we believed could reasonably explain variation in nest survival. Water depth has been found to be a factor in nest site selection and nest success in other crane studies (Naylor et al. 1954, Littlefield and Ryder 1968, Walkinshaw 1973, Stern et al. 1987, Smith and Smith 1992). Those studies suggest that nest survival should increase with water depth because deeper water would deter mammalian predators more than shallower water or unflooded areas (Sargeant and Arnold 1984). Nest survival should also increase with concealment by vegetation; we used vegetation height class (VHC) as a measure of nest concealment. Tall residual or new vegetation can conceal nests from mammalian predators but has only been directly assessed in 2 studies (Urbanek and Bookhout 1992; S. Maxson and M. Riggs, Minnesota Department of Natural Resources, unpublished report). We did not include habitat type in the models because water depth and vegetation height reflected the primary features of habitat types that would likely affect nest predation. Also, vegetation height changed over the course of the nesting season with plant growth and provided a concurrent measure of vegetation for each interval. Land use was of 
direct interest for refuge management and directly affects vegetation, which in turn can influence predator activities. Apparent nest success rates reported by Drewien (1973) suggested nest success differed among grazed pasture, idled pasture, idled marsh, and hay land. Littlefield and Paullin (1990) and Littlefield et al. (2001) reported differences in nest success among hayed-grazed, burned, and idled fields in Oregon. We hypothesized that nest survival would be 1) highest in idled fields because of greater availability of nestbuilding material and better concealment of nests in spring, 2) lower in grazed fields because grazing and trampling lead to increased patchiness in cover and greater access and visibility for predators, and 3) low in areas burned the previous fall because of less residual vegetation, poorer concealment cover, and reduced availability of materials for building nest platforms, which could constrain nesting sites within a territory. Nest initiation date has been found to affect nest survival in a number of species (Flint and Grand 1996, Grand and Flint 1997, Dinsmore 2002, Traylor et al. 2004). Specifically, we hypothesized that nest survival for cranes at Grays Lake would be lower early in the nesting period because cranes and Canada geese are the earliestnesting species at Grays Lake and hence little alternative prey exists. We used mean interval date rather than nest initiation date because this date was specific to that interval. Year reflects other factors that are difficult to measure, including variation in weather conditions, predator communities, and availability of alternative prey.

Some categories had to be dropped or merged for analysis because of insufficient sample sizes. We included only the 3 most common land-use categories (idle, fall graze, and summer graze) because of limited sample size in burned and hayed categories; the 3 categories retained are the most widespread land-use practices within the Grays Lake basin. We combined the 2 shortest vegetation height classes into one class and the 2 tallest classes into one class; hence, the final data set included 3 classes $(1=<30 \mathrm{~cm}, 2=30-60 \mathrm{~cm}$, and $3=>60 \mathrm{~cm}$ ).

Data on water depth and VHC usually were missing for most remote observations and for some observations in 1997. We recognized we could not exclude those intervals with missing data without introducing bias because intervals associated with nearly all remote observations were successful, and status of nest could have influenced whether a direct observation was conducted (i.e. if observer noted apparent failure, a direct check likely would have been done). Water depth and VHC were of specific interest for analyses; therefore, we estimated missing values using several approaches, recognizing change in both parameters were year-specific. If values for previous and subsequent visits were the same and, for water depths, data from other nests during the corresponding period showed little change, we used the same value. If missing data occurred $\leq 5$ days of prior and subsequent direct observations, we interpolated using data for that nest. If missing data occurred $>5$ days from direct observations, we interpolated a value using data from other nests or from water-gauge readings of water depths during the corresponding period. We estimated $\mathrm{VHC}$ by determining the most common frequency of VHC for the corresponding 10-day period for that habitat type.

Models were examined by fitting generalized linear mixed models with a binomial response distribution and the following modified logit link function:

$$
g(\theta)=\log \left(\frac{\theta^{1 / t}}{1-\theta^{1 / t}}\right)
$$

where $\theta$ is the interval survival rate and $t$ is the interval length in days (Shaffer 2004). Nest outcome for each observation interval was modeled as a binary variable $(0=$ failure, 1 = success) using PROC GENMOD (SAS Institute 2002). We used Akaike's Information Criterion for small samples ( $\mathrm{AIC}_{i} ;$ Burnham and Anderson 2002) to evaluate the support for each model. We evaluated models based on the degree of support as measured by $\mathrm{AIC}_{c}$ and normalized Akaike weights $\left(w_{i}\right)$. We considered models with $\Delta \mathrm{AIC}_{c} \leq 2$ to have substantial support, whereas we considered models with $\Delta \mathrm{AIC}_{c} \geq 4$ to have little or no empirical support from the data (Burnham and Anderson 2002). We calculated daily nest survival rates (DSRs; Shaffer 2004) using the following equation:

$$
D S R=\frac{e^{\beta_{0}+\beta_{1} x_{1}+\ldots \beta_{p} x_{p}}}{1+e^{\beta_{0}+\beta_{1} x_{1}+\ldots \beta_{p} x_{p}}}
$$

where $\beta_{0}$ is the intercept and $\beta_{1}-\beta_{p}$ are the regression coefficients for the variables in the model. We calculated nest success rates as $\operatorname{DSR}^{30}$ (30-d incubation period; Drewien 1973).

We also used logistic-exposure regression methods to examine the effects of year, the 4 management treatments, and their interaction, for nests found in the 12 experimental units. We used orthogonal contrasts in PROC GENMOD (SAS Institute 2002) to examine differences in nest survival among fields before treatments were applied (pretreatment, 1997-1998) and posttreatment (1999-2000).

We evaluated relationships between historic and current nest numbers in the basin core using a projected estimate. In 1997-2000, we had access to only $54(65 \%)$ of the 83 fields (defined for our study) in the basin core that were searched for nests during 1970-1971 (Drewien 1973). Therefore, we used a difference estimator (Scheaffer et al. 1986) to estimate change in average nest numbers (excluding renests in our study) in each field and thereby project current numbers of crane nests for the entire area. The primary assumption for this approach was that crane nest numbers were independent of field selection in 1997-2000; this seemed reasonable because fields were included or excluded from sampling during 1997-2000 because of access, not because of nest density or occurrence. Another assumption was that changes in nest density among fields searched during both periods (1970-1971 and 1997-2000) were representative of changes in fields not searched in 19972000. We assigned 1970-1971 nest locations to fields by scanning and georeferencing figure 1 in Drewien (1973:79) and superimposing the resultant coordinates of nest 
Table 1. Local population of greater sandhill cranes (no. and \%), by social groupings, counted during spring of 1998-2000 at Grays Lake, Idaho, USA.

\begin{tabular}{|c|c|c|c|c|c|c|c|c|c|c|}
\hline \multirow[b]{2}{*}{ Yr } & \multirow[b]{2}{*}{ Date } & \multicolumn{2}{|c|}{ Singles } & \multicolumn{2}{|c|}{ Pairs $^{\mathrm{a}}$} & \multirow{2}{*}{$\frac{\text { Indicated pairs }^{\mathrm{b}}}{\text { No. }}$} & \multicolumn{2}{|c|}{ Groups } & \multirow{2}{*}{$\frac{\text { Total cranes }}{\text { No. }}$} & \multirow{2}{*}{$\frac{\text { Projected total }^{\mathrm{C}}}{\text { No. }}$} \\
\hline & & No. & $\%$ & No. & $\%$ & & No. & $\%$ & & \\
\hline \multirow[t]{7}{*}{1998} & $14 \mathrm{Apr}^{\mathrm{d}}$ & 10 & 2 & 129 & 56 & 139 & 191 & 42 & 459 & 470 \\
\hline & $21 \mathrm{Apr}$ & 24 & 3 & 237 & 66 & 261 & 222 & 31 & 720 & 797 \\
\hline & $23 \mathrm{Apr}$ & 19 & 3 & 222 & 67 & 242 & 204 & 30 & 667 & 751 \\
\hline & $28 \mathrm{Apr}$ & 23 & 3 & 232 & 64 & 255 & 244 & 33 & 731 & 807 \\
\hline & $29 \mathrm{Apr}$ & 27 & 4 & 237 & 64 & 264 & 236 & 32 & 737 & 795 \\
\hline & 5 May & 67 & 12 & 143 & 51 & 210 & 208 & 37 & 561 & 619 \\
\hline & Annual $\bar{x}$ & & & & & & & & 684 & 754 \\
\hline \multirow[t]{5}{*}{1999} & $29 \mathrm{Apr}$ & 120 & 15 & 235 & 61 & 355 & 187 & 24 & 777 & \\
\hline & 5 May & 215 & 31 & 145 & 41 & 360 & 196 & 28 & 701 & \\
\hline & 7 May & 281 & 36 & 159 & 41 & 440 & 176 & 23 & 775 & \\
\hline & 11 May & 219 & 36 & 123 & 40 & 342 & 148 & 24 & 613 & \\
\hline & Annual $\bar{x}$ & & & & & & & & 717 & \\
\hline \multirow[t]{6}{*}{2000} & $17 \mathrm{Apr}$ & 85 & 10 & 250 & 60 & 335 & 246 & 30 & 831 & \\
\hline & $20 \mathrm{Apr}$ & 53 & 7 & 256 & & 309 & 242 & 30 & 807 & \\
\hline & $28 \mathrm{Apr}$ & 133 & 19 & 176 & 63 & 309 & 216 & 31 & 701 & \\
\hline & 1 May & 184 & 28 & 148 & 44 & 332 & 187 & 28 & 667 & \\
\hline & 4 May & 187 & 28 & 150 & 45 & 337 & 176 & 27 & 663 & \\
\hline & Annual $\bar{x}$ & & & & & & & & 734 & \\
\hline
\end{tabular}

\footnotetext{
1 pair $=2$ cranes; percentages are based on no. of birds.

${ }^{\mathrm{b}}$ Indicated pairs $=$ no. of singles + no. of pairs (Drewien 1973).

c Slightly smaller survey area in 1998. Projection assumes that distribution of cranes was the same in 1998 as in 1999.

${ }^{\mathrm{d}}$ Census excluded in calculation of annual $\bar{x}$ because we judged that the entire population had not yet returned.
}

locations on our GIS layer of current field boundaries. We subdivided the basin core into 16 additional fields, not shown in Fig. 1, for this comparison. We recognize that the historic locations are not as accurate as our nest locations because of inaccuracies during creation of the figure (hand drafted from aerial photographs) and error from the scanning and georeferencing process. Location errors are indeed apparent in 2 regions of the basin, where nests appear to be located farther away from the emergent marsh than current nests. However, we believe that, although these errors likely introduced greater variability in differences, the differences resulting from inaccurate historical locations balanced out over the 83 fields (some would result in negative values, others positive values).

\section{RESULTS}

\section{Local Population 1998-2000}

During 1998-2000, the average local population of sandhill cranes in spring was 735 cranes (range 717-754, $n=3$ years; Table 1). Number of pairs ranged from 222 to 256 during mid- to late April and comprised $50-63 \%$ of the local population. Numbers of pairs dropped to approximately 150 in early May, coinciding with the beginning of nest initiation. In fields that we systematically searched during 1998-2000, total pair counts represented $93 \%, 114 \%$, and $103 \%$ of the number of total nests found (excluding renests) in 1998, 1999, and 2000, respectively.

\section{Nesting Ecology}

We collected information on 578 crane nests. We searched 3,186 ha and found 131 nests in 1997; 2,377 ha and 131 nests in 1998; 3,720 ha and 143 nests in 1999; and 3,988 ha and 173 nests in 2000. Common to all 4 years were searches on 29 fields totaling 2,132 ha, including the 805 ha of the 12 experimental fields. Nest densities in total area searched each year ranged from 0.038 nests/ha in 1999 to 0.054 nests/ ha in 1998.

Renesting accounted for $4.6 \%$ of total nests in 1997, $1.5 \%$ in $1998,10.5 \%$ in 1999 , and $8.0 \%$ in 2000 . Renests were initiated between late May to mid-June in 1997, 1998, and 1999; during 2000, renests were initiated between 11 May and 29 May. During 2000, we observed a second renesting attempt by 2 pairs of sandhill cranes. Each pair abandoned their first 2 nests because of investigator disturbance during egg laying and initiated a third nest.

Nest site characteristics.-Overall, we found $43.5 \%$ of nests in Baltic rush; wet meadow (17.3\%), cattail-bulrush $(18.1 \%)$, and sedge-cattail-bulrush $(10.5 \%)$ also were commonly used habitat types $(n=559)$. Relatively few nests were located in upland $(2.1 \%)$, sedge $(5.4 \%)$, open water $(1.3 \%)$, or other habitats $(1.8 \%)$. Results were similar among fields searched in all 4 years; we found most crane nests in Baltic rush $(46.9 \%)$, wet meadow $(20.5 \%)$, and cattail-bulrush $(16.4 \% ; n=433)$. In these fields, proportions of nests found in wet meadow declined and proportions of nests found in Baltic rush and cattail-bulrush increased from 1997 to 2000 (Fig. 3). Upland nests were most common in 1997 but uncommon in these fields in other years.

Average water depths at nests were lowest in $1997(\bar{x}=12$ $\mathrm{cm}, \mathrm{SE}=1, n=391$ observations), highest in $1998(\bar{x}=17$ $\mathrm{cm}, \mathrm{SE}=1, n=439)$ and $2000(\bar{x}=18 \mathrm{~cm}, \mathrm{SE}=1, n=453)$, and intermediate in $1999(\bar{x}=15 \mathrm{~cm}, \mathrm{SE}=1, n=431)$. Average water depths during 10-20 May, which reflect peak water levels during nest initiation and early incubation, indicated cranes located their nests in shallowly flooded 


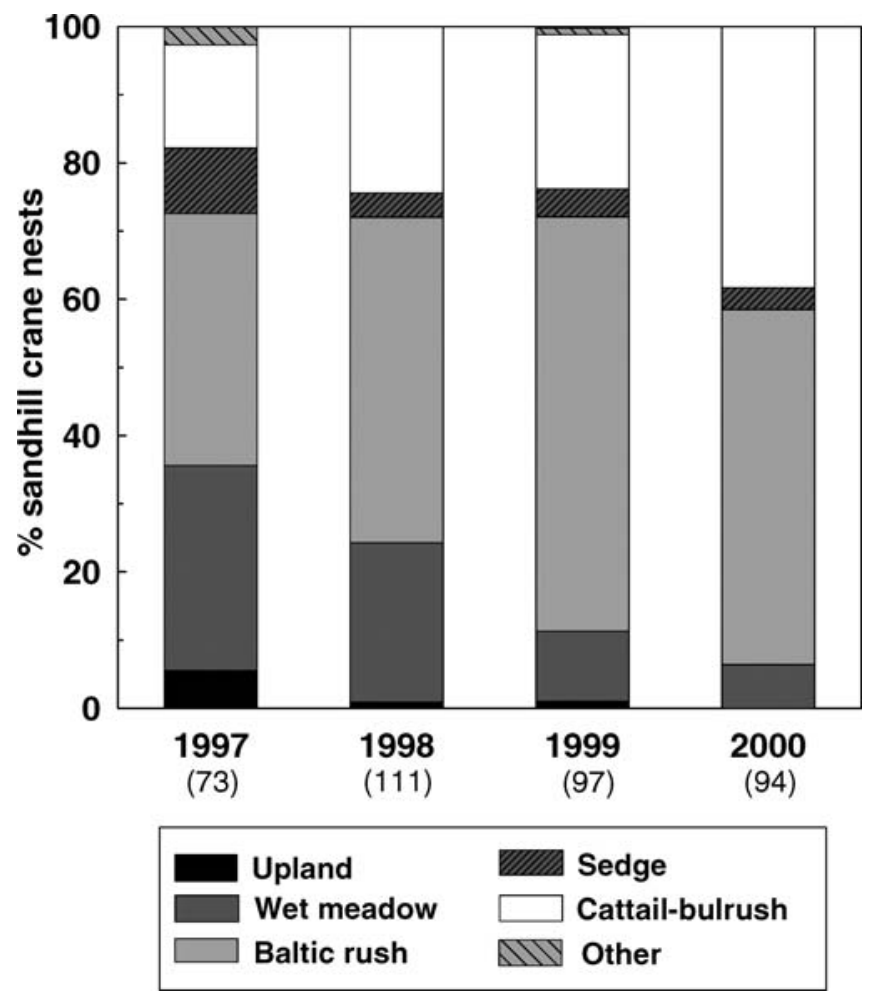

Figure 3. Distribution of sandhill crane nests among 6 habitat types for fields searched in all 4 years at Grays Lake, Idaho, USA, during 1997-2000. Numbers listed underneath years indicate the number of nests found that year. We included nests found in open water in the cattail-bulrush category.

areas in 1997 and much deeper areas in $2000(1997: \bar{x}=12$ $\mathrm{cm}, \mathrm{SE}=2, n=82 ; 1998: \bar{x}=19 \mathrm{~cm}, \mathrm{SE}=2, n=118 ; 1999$ : $\bar{x}=17 \mathrm{~cm}, \mathrm{SE}=2, n=108 ; 2000: \bar{x}=24 \mathrm{~cm}, \mathrm{SE}=2, n=$ 87). Average water depths during all years combined varied with habitat type, ranging from $4 \mathrm{~cm}(\mathrm{SE}=1, n=79)$ in wet meadow and $9 \mathrm{~cm}(\mathrm{SE}=1, n=154)$ in Baltic rush to $12 \mathrm{~cm}$ $(\mathrm{SE}=2, n=25)$ in sedge and $43 \mathrm{~cm}(\mathrm{SE}=2, n=92)$ in cattail-bulrush. Successful nests tended to be in deeper water $(\bar{x}=15.4 \mathrm{~cm}, \mathrm{SE}=1.1, n=312)$ than unsuccessful nests $(\bar{x}=9.7 \mathrm{~cm}, \mathrm{SE}=1.1, n=193)$ at their termination date.

Vegetation height classes recorded at nests varied across the nesting season and among years (Fig. 4), reflecting both seasonal vegetation growth and habitat in which a nest was located. In 1997, vegetation heights around crane nests remained low through early June, whereas in 2000, vegetation heights around nests were $>30 \mathrm{~cm}$ from midMay onward. During late April-10 May, when $>60 \%$ nests were initiated, $41 \%$ of nests were in vegetation $<10 \mathrm{~cm}$ tall, $43 \%$ in vegetation $10-30 \mathrm{~cm}$ tall, $6 \%$ in vegetation $30-60$ $\mathrm{cm}$ tall, and $10 \%$ in vegetation $>60 \mathrm{~cm}$ tall. The latter 2 categories represented only cattail-bulrush. By early June, when $>50 \%$ of nests had been terminated, $5 \%$ of nests were in vegetation $<10 \mathrm{~cm}$ tall, $16 \%$ in vegetation $10-30$ $\mathrm{cm}$ tall, $45 \%$ in vegetation $30-60 \mathrm{~cm}$ tall, and $34 \%$ in vegetation $>60 \mathrm{~cm}$ tall.

Nest survival in all fields.-Apparent nest success ranged from a high of $72 \%$ in 1998 to a low of $51 \%$ in

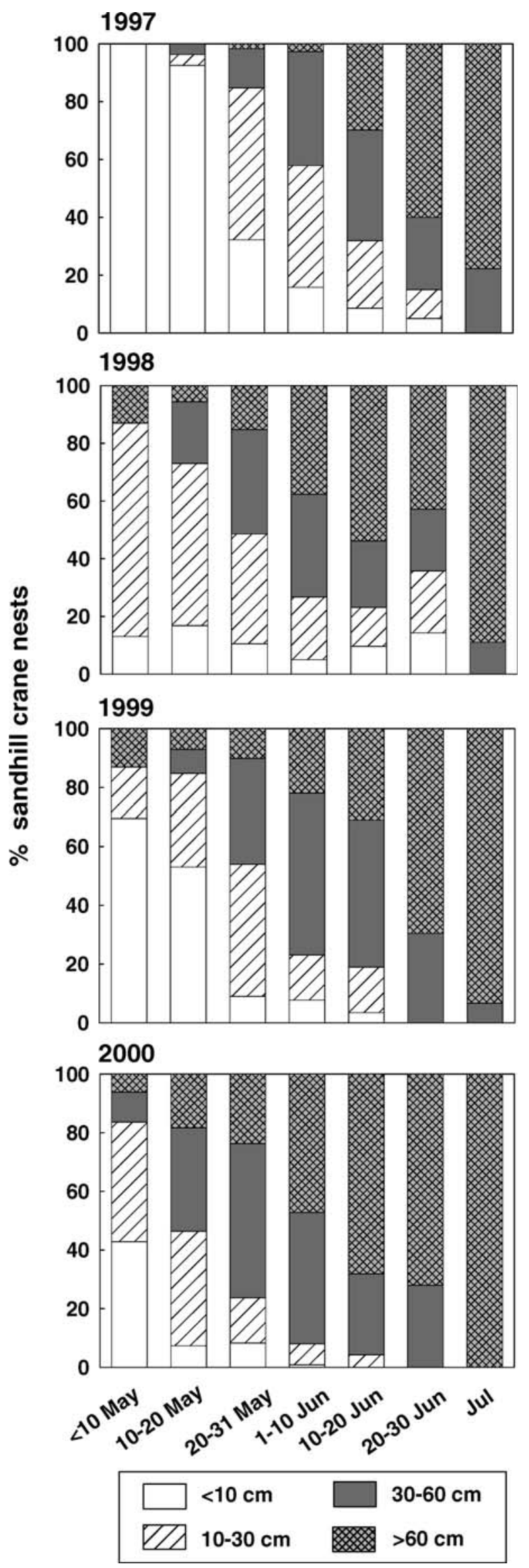

Figure 4. Percentage of occurrence of sandhill crane nests in 4 categories of vegetation height, by year and by 10-day periods, at Grays Lake, Idaho, USA, during 1997-2000. 
Table 2. Logistic-exposure models for nest survival of greater sandhill cranes at Grays Lake, Idaho, USA, during 1997-2000, with corresponding number of parameters $(K), \log$-likelihood values, and Akaike's Information Criterion $\left(\mathrm{AIC}_{c}\right)$ scores and weights $\left(w_{i}\right)$. Models are ranked by $\Delta$ AIC $c$ values. Model parameters include year (YEAR), water depth (WDEPTH), vegetation height class (VHC), land use in the previous year (USE), and mean interval date (MINT).

\begin{tabular}{|c|c|c|c|c|c|}
\hline Model & $K$ & Log-likelihood & $\mathrm{AIC}_{c}$ & $\Delta \mathrm{AIC}_{c}$ & $w_{i}$ \\
\hline YEAR, WDEPTH, YEAR $\times$ WDEPTH & 8 & -416.695 & 849.415 & 0.000 & 0.6077 \\
\hline YEAR, WDEPTH & 5 & -420.935 & 851.880 & 2.465 & 0.1772 \\
\hline YEAR, WDEPTH, MINT & 6 & -420.714 & 853.443 & 4.028 & 0.0811 \\
\hline YEAR, WDEPTH, VHC & 7 & -420.247 & 854.514 & 5.099 & 0.0475 \\
\hline WDEPTH & 2 & -425.656 & 855.313 & 5.898 & 0.0318 \\
\hline YEAR, WDEPTH, MINT, WDEPTH $\times$ MINT & 7 & -420.707 & 855.434 & 6.019 & 0.0300 \\
\hline YEAR, WDEPTH, VHC, USE & 9 & -420.072 & 858.175 & 8.760 & 0.0076 \\
\hline YEAR, WDEPTH, VHC, USE, MINT & 10 & -419.148 & 858.295 & 8.919 & 0.0070 \\
\hline YEAR, VHC, USE, YEAR $\times$ VHC, YEAR $\times$ USE & 5 & -424.387 & 858.784 & 9.369 & 0.0056 \\
\hline YEAR & 4 & -426.500 & 861.006 & 11.591 & 0.0020 \\
\hline WDEPTH, VHC, USE & 6 & -424.891 & 861.797 & 12.383 & 0.0012 \\
\hline YEAR, MINT & 5 & -426.014 & 862.038 & 12.623 & 0.0011 \\
\hline Constant survival & 1 & -431.693 & 865.386 & 15.972 & 0.0002 \\
\hline MINT & 2 & -431.038 & 866.079 & 16.664 & 0.0001 \\
\hline $\begin{array}{l}\text { Global model: YEAR, WDEPTH, VHC, USE, MINT, YEAR } \times \text { WDEPTH, } \\
\text { YEAR } \times \text { MINT, WDEPTH } \times \text { MINT, YEAR } \times \text { VHC, YEAR } \times \text { USE, VHC } \times \text { USE }\end{array}$ & 33 & -405.779 & 877.952 & 28.538 & 0.0000 \\
\hline
\end{tabular}

2000 , with an overall mean of $60 \%(n=519$ nests $)$. The constant-survival (no effects) model from logistic-exposure analysis yielded an overall DSR of 0.9709 , or a nest success rate of $41.2 \%$. Of 206 nests categorized as failed, $92.7 \%$ were destroyed by predators, $0.5 \%$ by livestock, and $6.8 \%$ by unknown causes.

We examined 15 models, including constant survival, in our analysis of nest survival for all nests monitored during 1997-2000 ( $n=911$ interval observations of 481 nests; AIC $_{c}$ sample size $=5,724$ [Rotella et al. 2005]). The model with the lowest $\Delta \mathrm{AIC}_{c}$ score included year, water depth, and year $\times$ water depth interaction (Table 2). The second model included only year and water depth. All other models had $\Delta \mathrm{AIC}_{c}$ scores $>4$. Daily survival rates were highest and had the smallest confidence intervals in 1998, with lower and more variable survival in other years (Fig. 5). The DSRs changed little relative to water depth in 1998 but changed markedly with water depth in 2000 (Fig. 6).

Nest survival in experimental fields.-In the BACI experiment in the 12 experimental fields, nest survival was affected by year $\left(\chi_{3}^{2}=11.43, P=0.010\right)$ but not by

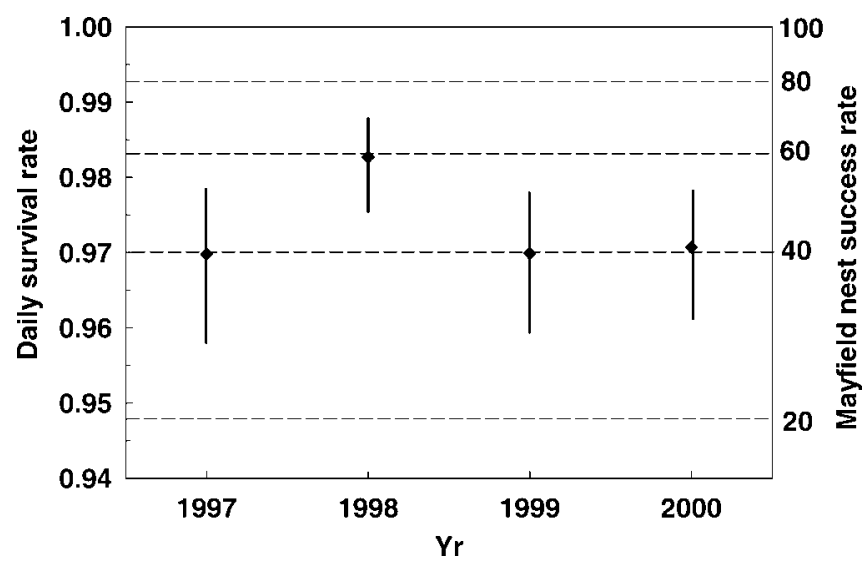

Figure 5. Daily nest survival rates and 95\% confidence intervals of sandhill crane nests at Grays Lake, Idaho, USA, during 1997-2000. treatment $\left(\chi_{3}^{2}=6.06, P=0.109\right)$ or the interaction between year and treatment $\left(\chi_{9}^{2}=2.98, P=0.965\right.$; Fig. 7). Daily survival rates were higher in $1998(\mathrm{DSR}=0.9845)$ than in $1999\left(0.9591 ; \chi^{2}{ }_{1}=6.59, P=0.010\right)$ and $2000\left(0.9572 ; \chi_{1}^{2}\right.$ $=7.78, P=0.005)$ but were similar to DSRs in 1997 $\left(0.9717 ; \chi^{2}{ }_{1}=2.53, P=0.112\right)$. We found no differences among treatments before treatment applications for 1997 or 1998 ( $P \geq 0.140$ ). Examination of nest survival before versus after treatment (1997-1998 vs. 1999-2000) revealed differences only in fall-burn fields $\left(\chi^{2}{ }_{1}=4.29, P=0.038\right)$, where average DSR fell from 0.9781 (51.4\% nest survival) in pretreatment years to $0.9503(21.7 \%$ nest survival) posttreatment.

Nest densities. - We examined the distribution of nests reported in 1970-1971 (Drewien 1973) relative to nests located during our study to extrapolate our data from the fields searched during our study to the larger area of the basin core searched during the 1970s (Fig. 8). The annual mean number of nests found per field was estimated at 2.00 for 1970-1971 ( $\mathrm{SE}=0.33$; range $0-13.5, n=83$ fields) and 2.75 ( $\mathrm{SE}=0.19$; range 0-9.8; $n=54$ fields) for 1999-2000, a difference of +0.75 nests per field ( $37 \%$ higher). From this, we projected annual average number of nests (excluding renests and hence equals number of breeding pairs) in the basin core for $1999-2000$ at $228(2.75 \times 83=228 ; 95 \% \mathrm{CI}$ $=198-259)$.

\section{DISCUSSION}

\section{Nesting Ecology}

Factors influencing nest survival.-Year and water depth and their interaction were key factors influencing nest success of sandhill cranes at Grays Lake. These results are consistent with our hypothesis that nest survival would increase with water depth. Water provides the clearest mechanism for affecting nest survival, by limiting movements of mammalian predators and hence their encounters with nests (Sargeant and Arnold 1984). 


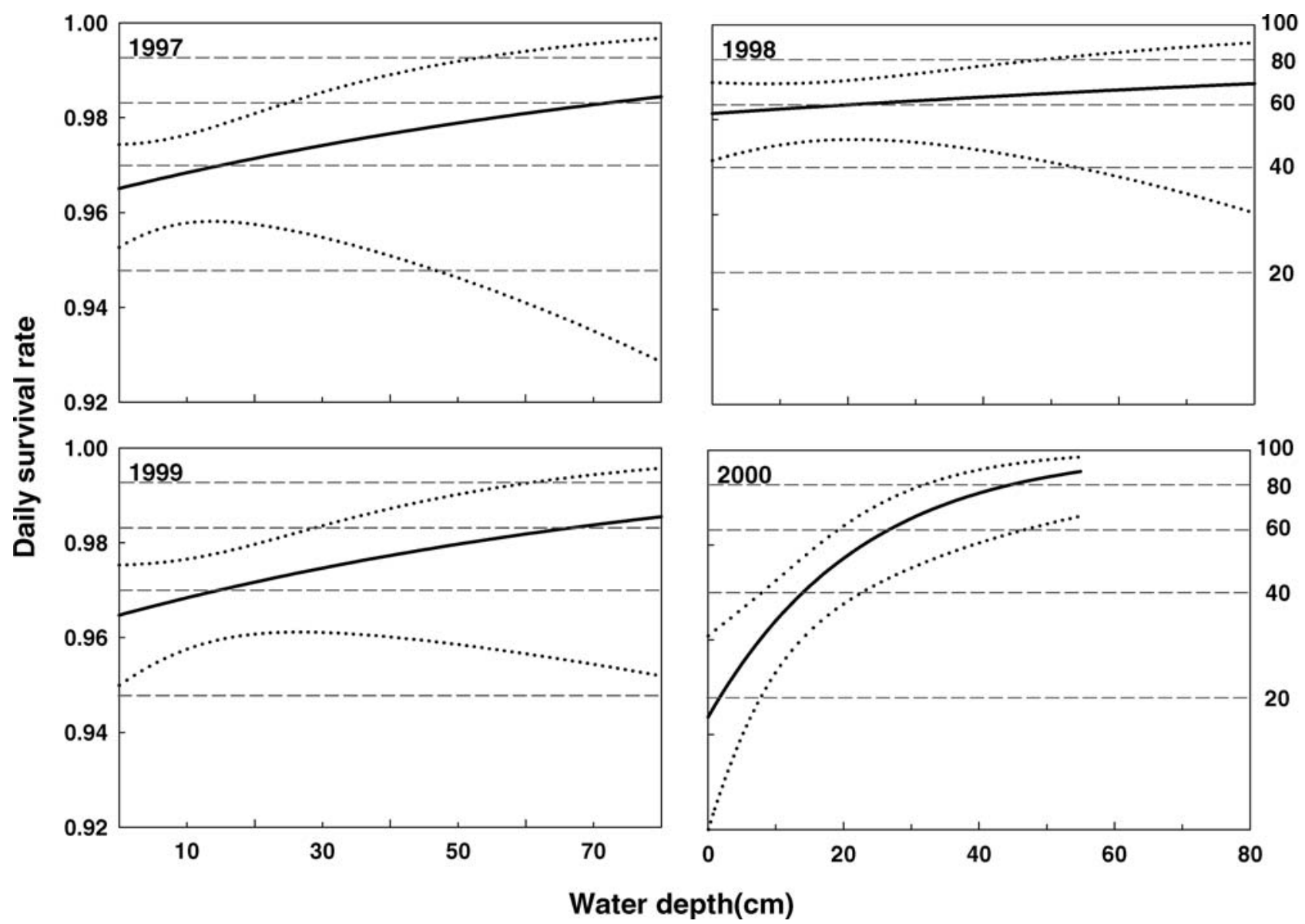

Figure 6. Models of daily survival rates and $95 \%$ confidence intervals of sandhill crane nests during 1997-2000 at Grays Lake, Idaho, USA, relative to water depth at nest.

The interaction of water depth and year might be expected, as year reflects annual variation in a number of factors affecting nest site conditions, including other components of water condition not captured by water depth, such as spatial extent of flooding at a larger scale (e.g., hundreds of square meters) and timing of flooding relative to nest initiation. The extent of flooding during the main nest initiation period (late Apr to mid-May), as indicated by the high water levels in Fig. 2, was greatest in 1997. Under those conditions, large areas of the basin core were isolated from the contiguous mainland and hence isolated from mammalian predators. However, the extremely high water levels in that year likely also flooded some habitats, such as cattail-bulrush, too deeply for construction of nest platforms, resulting in cranes nesting in more shallowly flooded areas and habitats. In contrast, the low water conditions during this same period in 2000 resulted in a much greater area of the basin core, including Baltic rush and some cattail-bulrush habitats, being accessible by mammalian predators, and we found their sign much farther into the marsh that year than in previous years. Consequently, cranes nested at sites and in habitats with deeper water, and water depths had the greatest influence on nest survival that year. Despite the relationship between predation and water depth, we found no support for our hypothesis that nest survival varied with date.

Nest survival in 1998 was higher than in 1999 and was largely unrelated to water depth, even though the extent and timing of flooding in 1998 was similar to that of 1999 . We suspect this difference in nest survival was related to a second aspect reflected by the year effect, the distribution and abundance of alternative prey for nest predators. Smallmammal trapping conducted concurrently with our study showed microtine populations irrupted in 1998, then declined to 1997 levels in 1999 and 2000 (Austin and Pyle 2004). Capture rates of montane voles (Microtus montanus) and meadow voles (Microtus pennsylvanicus) combined were 6 times higher in 1998 than in other years. Nest survival was highest and least variable in 1998, the year of highest alternative prey. At Grays Lake, extensive spring flooding as experienced in 1997-1999 forced small mammals from meadow to upland habitats and, therefore, would also have encouraged predators to hunt more actively in those drier sites than in wetter areas where cranes nested. These results suggest that availability of alternate prey influences nest success and that nest site conditions are most important when predators have fewer choices for prey.

Models including vegetation height received little support although vegetative cover has been shown to be an 


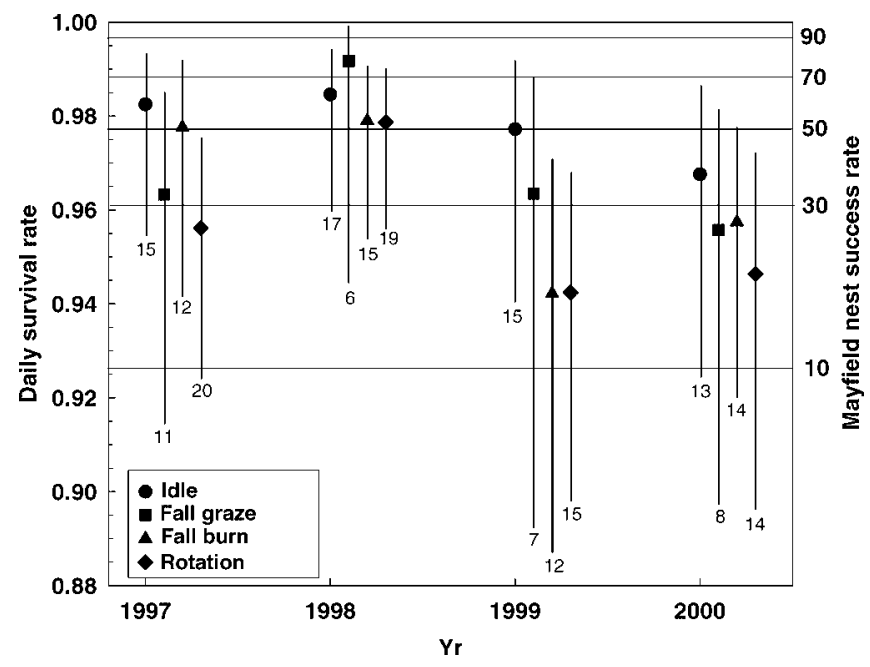

Figure 7. Daily nest survival rates and $95 \%$ confidence intervals of sandhill crane nests, by year and treatment, on 12 experimental units during 19972000 at Grays Lake, Idaho, USA. Numbers under the error bar indicate number of nests in sample.

important factor in nest site selection and nest survival elsewhere (Littlefield and Ryder 1968; Smith and Smith 1992; Littlefield 1995, 2001). S. Maxson and M. Riggs (unpublished report) suggested that cranes may select sites with some vertical structure but not extensive concealment; in shallowly flooded sites, however, effects of concealment are often overwhelmed by predation risk. The low ranking of vegetation height in our models may also be related to the simplicity of our measure, which provided an incomplete representation of visual obstruction.

Results from the experimental fields supported only 1 of our 3 hypotheses related to habitat management, that fall burning would reduce nest success. Burn treatments in fall 1998 removed most residual vegetation in all habitats and, therefore, reduced availability of nest-building materials and potential nesting cover. The absence of residual vegetation likely prevented cranes from building nest platforms in more deeply flooded areas and reduced their other options for nest sites (e.g., in more shallowly flooded areas or unburned, residual cattail-bulrush). In comparison, the 2 grazing treatments had much less-extensive impact on residual vegetation, particularly in cattail-bulrush (J. E. Austin, unpublished report). Idled habitat did not appear to provide substantial improvement to nest survival, although nest survival in idled fields tended to be higher during the 2 posttreatment years than in other fields (Fig. 7). The lack of treatment effect for grazing and idle treatments is not surprising considering that habitat management practices affect primarily vegetative structure and the low support for $\mathrm{VHC}$ in the $\mathrm{AIC}_{c}$ models for all nests.

Comparisons to earlier studies. - The first study of nesting birds at Grays Lake, conducted during 1940-1951, reported apparent nest success for sandhill cranes at $90 \%$ (Steel 1952). Apparent nest success during 1969-1971 was $78 \%$ (Drewien 1973). During a period with intensive predator control at Grays Lake, coinciding with a whooping crane (Grus americana) cross-fostering project (1977-1989),

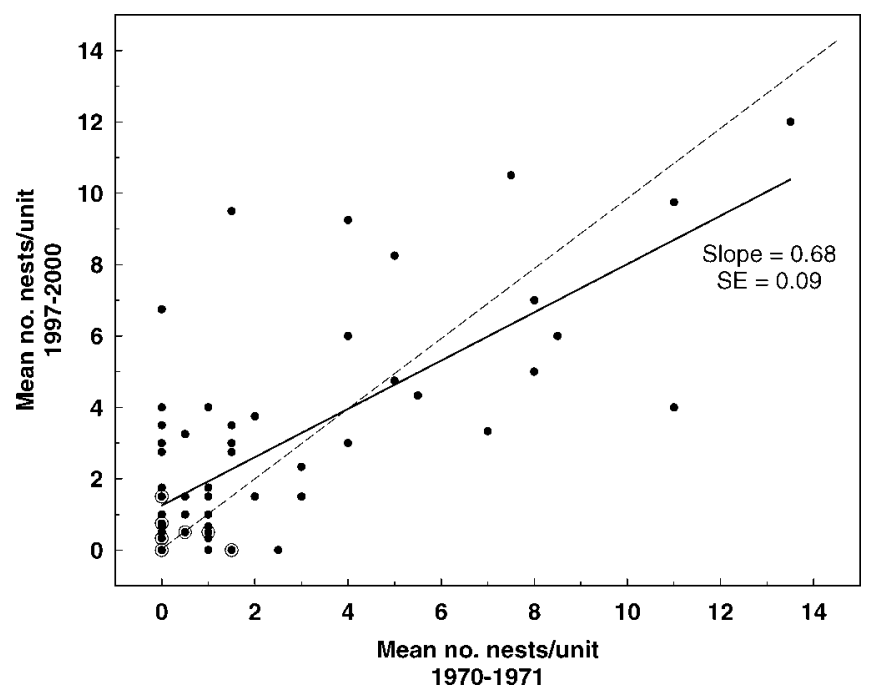

Figure 8. Mean number of sandhill crane nests (excluding renests) on fields during 1970-1971 (Drewien 1973) versus 1999-2000 at Grays Lake, Idaho, USA. The dashed line represents a 1:1 correspondence (i.e., no change) in nest numbers per unit between time periods. Circled points represent multiple data points.

apparent nest success was 94\% (Drewien and Bouffard 1990). During our study, apparent nest success averaged $60 \%$, indicating that nest success has generally continued to decline over the past 50 years.

What has changed? Water level management at Grays Lake has remained relatively consistent over this time period, and water levels during spring 1969-1970 (USFWS, unpublished data), the only period for which we have data, were similar to that during spring 1998 and 1999, suggesting that flooding conditions were generally similar. We have little direct or quantitative evidence of substantial changes in habitat conditions. Interviews with local landowners indicate that land use in the Grays Lake Valley has changed substantially over the past 25 years as practices on private lands have shifted, including substantial declines in amount of meadow and grassland hayed, a substantial increase in total area of meadow and grassland seasonally grazed by cattle, and substantial reduction in area of upland cultivated for barley production (replaced by permanent cover in the Conservation Reserve Program; R. Stoor, USFWS, personal communication). Grazing impacts on residual cover likely have lessened because of the shift from cow-calf livestock grazed for a longer season toward mostly yearling livestock grazed for a shorter summer or fall season. On refuge lands, area in idle cover has increased from none before 1985 to a peak of 1,113 ha in 1996-1997. These land-use changes in the Grays Lake Valley likely have altered residual vegetation and habitat conditions, from previous extensive areas of short cover in meadows and uplands to higher residual cover in many areas today. However, the lack of evidence in our study that vegetation or grazing influence nest survival suggests that these changes likely have not directly contributed to declining nest survival.

Concurrent with these changes, and likely interacting with 
habitat changes, are changes in the predator community. Nest depredations in the early 1970s and 1980s were attributed to skunks (Mephitis mephitis), crows, and ravens (Drewien 1973, Drewien and Bizeau 1977). Coyotes (Canis latrans) were uncommon during the 1970s because they were the main target of control by local ranchers for most of the century; they were also the main target of intensive predator control during the whooping crane cross-fostering study (1977-1989), when reported rates of nest success were $>90 \%$ (Drewien et al. 1985, Drewien and Bouffard 1990). Use of the predicide compound 1080 was eliminated in 1972, and intensive predator control by USFWS was terminated after 1989; hence, we suspect that coyote populations in the Grays Lake Valley are now higher than they were during the previous studies. Corvid populations in the area also were presumably depressed until the mid-1980s by effects of predicides, but their numbers have increased since the 1960s over much of their range in North America (Boarman and Heinrich 1999). Also notable is the invasion of red fox (Vulpes vulpes); this predator was first noted in the valley in 1970 and was commonly observed in wet meadows and grasslands during our study (J. E. Austin, unpublished report). Overall, we suspect changes in the predator community, interacting with habitat changes that affect predator movements and alternative prey, have been a major factor contributing to declines in nest success rates. The strong support for water depth in our models suggests mammalian predators are more important nest predators than avian predators at Grays Lake.

\section{Population}

Local population.-The average local population during spring 1998-2000 (735) was 34\% higher than that reported for May 1970-1971 ( $\bar{x}=549$; Drewien 1973). Numbers of pairs in late April 1998-2000 were similar to counts of indicated pairs (no. of pairs + no. of single birds during breeding season; Drewien 1973) during 1970-1971, but we estimated the number of nests in the basin core has increased 14\% (from Drewien's estimate of 200 in 1971 to 228 in 1999-2000). This higher number of nests may be due to underestimation of what proportion of our nests were renests, although careful examination of the data does not support this. Nest densities in the basin core may also have increased if cranes have shifted their nesting territories from areas outside to inside the core. Such a shift may have occurred if recent pressures by mammalian predators have forced cranes off marginal territories and nesting sites adjacent to the core to more secure areas within the core. As a proportion of the population, peak pair counts in late April of 1999 and 2000 (61\% and 63\%, respectively) closely match the proportion of breeding birds based on estimated nests, derived independently ( 228 nests $\times 2 /$ total population of 717 [1999] or 734 [2000], or 62-63\% of the population). Our estimate of nest numbers in 1971 suggests $60 \%$ of the population were breeding that year $(166 \times 2 / 549$ total cranes). Drewien's (1973) estimate of 200 nests, however, would suggest $73 \%$ of the population was breeding that year.
We found the increased size of the local population surprising given the number of local and regional factors that likely negatively affected the population during the intervening 27-30 years: moderate to severe drought during 1986-1992, substantial changes in the local predator community, and decreased nest success and recruitment. The current local population of sandhill cranes likely includes many individuals recruited during the 1970s and early 1980s. We suggest that high recruitment during 1975-1983, high adult survival (Drewien et al. 1995), and strong natal philopatry (R. C. Drewien et al., USFWS, unpublished report) likely have maintained the population at Grays Lake through a period of low recruitment in the 1990s. Although limits of that demographic resilience are unknown, we question whether the local population can maintain itself indefinitely at rates of nest success and recruitment observed, unless it is augmented through immigration. Alternatively, sandhill cranes may rely on periodic years of good production to sustain their population, such as the $11 \%$ production recorded in refuge surveys in fall 2004 (C. Mitchell, USFWS, personal communication). Indeed, census data during 2001-2006 indicates that the population at Grays Lake has declined since our study, from 689 cranes in 2001 to 588 in $2006(\bar{x}=630$ cranes; USFWS, unpublished data).

\section{MANAGEMENT IMPLICATIONS}

Water conditions at Grays Lake strongly influence survival of crane nests at Grays Lake. Delaying or reducing the rate of water withdrawal during the nesting period could reduce nest predation. Maintaining May water levels at or above their long-term median (1,946.82-1,946.87 $\mathrm{m}$ above mean sea level elevation in 2000; Fig. 2) would optimize availability of suitable nesting habitats and increase nest survival. Drought will limit options to manage water levels in some years, and any long-term strategy should incorporate natural annual variation in water levels (Laubhan et al. 2005). Changes in water management will require renegotiation of agreements among the United States Bureau of Indian Affairs, USFWS, and private landowners. Annual censuses of total crane numbers and pairs in late April are essential so that managers can monitor population trends relative to habitat conditions.

We found no support for earlier concerns about the potential negative impacts of grazing or idling wetland habitat for nesting cranes. The short-term negative effects of fall burning could be ameliorated by limiting the frequency of fall burning to allow rebuilding of residual vegetation. Our study only evaluated immediate, short-term impacts of these treatments, and only long-term monitoring can fully address the implications of habitat management practices for nesting sandhill cranes.

\section{ACKNOWLEDGMENTS}

This study was supported by the USFWS-Region 1 . Additional in-kind support was provided by the Montana 
Cooperative Wildlife Research Unit and the Northern Prairie Wildlife Research Center. We thank Refuge Manager M. Fisher and Refuge Biologist W. Pyle for their interest and support at all levels during the study. F. Paveglio and USFWS Project Leaders at the Southeast Idaho Area Complex office provided administrative support during the course of the study. We appreciate the dedication of many individuals who conducted the field work for this study. T. Sklebar provided GIS assistance and D. Buhl provided statistical advice. We thank D. Buhl, R. Drewien, G. Ivey, and 2 anonymous reviewers for comments and contributions to this manuscript.

\section{LITERATURE CITED}

Austin, J. E., and W. H. Pyle. 2004. Small mammals in montane wet meadow habitat at Grays Lake, Idaho. Northwest Science 78:225-233.

Boarman, W. I., and B. Heinrich. 1999. Common raven (Corax corax). Account 476 in A. Poole and F. Gill, editors. The birds of North America. The Birds of North America, Philadelphia, Pennsylvania, USA.

Burnham, K. P., and D. R. Anderson. 2002. Model selection and multimodel inference: a practical information-theoretic approach. Second edition. Springer-Verlag, New York, New York, USA.

Clark, T. W., S. C. Minta, A. P. Curlee, and P. M. Kareiva. 1999. A model of ecosystem for carnivores in Greater Yellowstone. Pages 1-9 in T. W. Clark, A. P. Curlee, S. C. Minta, and P. M. Kareiva, editors. Carnivores in ecosystems: the Yellowstone experience. Yale University Press, New Haven, Connecticut, USA.

Coleman, R. A., N. Fuller, J. P. Mazzoni, R. Berry, J. Davis, D. Adams, D. G. Young, R. Fries, and T. Heuer. 1990. Report to the Director: a review of secondary uses occurring on national wildlife refuges. U.S. Fish and Wildlife Service, Washington, D.C., USA.

Dinsmore, S. J, G. C. White, and F. L. Knopf. 2002. Advanced techniques for modeling avian nest survival. Ecology 83:3476-3488.

Drewien, R. C. 1973. Ecology of Rocky Mountain greater sandhill cranes. Dissertation, University of Idaho, Moscow, USA.

Drewien, R. C. 1997. Changes in sandhill crane numbers at Grays Lake, Idaho. Unison Call 9:6

Drewien, R. C., and E. G. Bizeau. 1974. Status and distribution of sandhill cranes in the Rocky Mountains. Journal of Wildlife Management 38: 720-742.

Drewien, R. C., and E. G. Bizeau. 1977. Cross-fostering whooping cranes to sandhill crane foster parents. Pages 201-222 in S. A. Temple, editor. Endangered birds: management techniques for preserving endangered species. University of Wisconsin Press, Madison, USA.

Drewien, R. C., and S. H. Bouffard. 1990. Predator control of whooping crane and sandhill crane production at Grays Lake National Wildlife Refuge, Idaho. Pages 8-9 in Proceedings of the symposium on managing predation to increase production of wetland birds, Northern Prairie Wildlife Research Center, 15-17 August 1990, Jamestown, North Dakota, USA.

Drewien, R. C., S. H. Bouffard, D. D. Call, and R. A. Wonacott. 1985. The whooping crane cross-fostering experiment: the role of animal damage control. Pages 7-13 in P. T. Bromley, editor. Proceedings of the Second Eastern Wildlife Damage Control Conference, North Carolina State University, 22-25 September 1985, Raleigh, North Carolina, USA.

Drewien, R. C., W. M. Brown, and W. L. Kendall. 1995. Recruitment in Rocky Mountain greater sandhill cranes and comparison with other crane populations. Journal of Wildlife Management 59:339-356.

Ellis, D., G. F. Gee, and C. M. Mirande, editors. 1996. Cranes: their biology, husbandry and conservation. U.S. Department of the Interior, National Biological Service, Washington, D.C., and International Crane Foundation, Baraboo, Wisconsin, USA.

Flint, P. L., and J. B. Grand. 1996. Nesting success of the northern pintail on the coastal Yukon-Kuskokwim Delta, Alaska. Condor 98:54-60.
Gee, G. F. 1983. Crane reproductive physiology and conservation. Zoo Biology 2:199-213.

Grand, J. B., and P. L. Flint. 1997. Productivity of nesting spectacled eiders on the lower Kashunuk River, Alaska. Condor 99:926-932.

Greenwood, R. J., and A. B. Sargeant. 1995. Effect of a commonly used nest marker on nest success of ducks in prairie Canada. Canadian Field Naturalist 109:437-440.

Klett, A. T., H. F. Duebbert, C. A. Faanes, and K. F. Higgins. 1986. Techniques for studying nest success of ducks in upland habitats in the Prairie Pothole Region. U.S. Fish and Wildlife Service Resource Publication 158, Washington, D.C., USA.

Laubhan, M. K., S. L. King, and L. H. Fredrickson. 2005. Managing inland wetlands for wildlife. Pages 797-838 in C. L. Braun, editor. Techniques for wildlife investigations and management. Sixth edition. Port City Press, Baltimore, Maryland, USA.

Littlefield, C. D. 1995. Sandhill crane nesting habitat, egg predators, and predator history at Malheur National Wildlife Refuge, Oregon. Northwestern Naturalist 76:137-143.

Littlefield, C. D. 2001. Sandhill crane nest and egg characteristics at Malheur National Wildlife Refuge, Oregon. Proceedings North American Crane Workshop 8:40-44.

Littlefield, C. D., J. E. Corneley, and B. D. Ehlers. 2001. Effects of an early spring burn on greater sandhill crane nesting success at Malheur National Wildlife Refuge, Oregon. Proceedings North American Crane Workshop 8:45-47.

Littlefield, C. D., and D. G. Paullin. 1990. Effects of land management on nesting success of sandhill cranes in Oregon. Wildlife Society Bulletin 18: 63-64.

Littlefield, C. D., and R. A. Ryder. 1968. Breeding biology of the greater sandhill crane on Malheur National Wildlife Refuge, Oregon. Transactions of North American Wildlife and Natural Resources Conference 33:440-454.

Mirande, C. M., G. F. Gee, A. Burke, and P. Whitlock. 1996. Egg and semen production. Pages 45-58 in D. H. Ellis, G. F. Gee, and C. M Mirande, editors. Cranes: their biology, husbandry, and conservation. U.S. Department of Interior, National Biological Service, Washington, D.C., and International Crane Foundation, Baraboo, Wisconsin, USA.

National Oceanographic and Atmospheric Administration. 2002. Idaho climate summaries. Henry, Idaho (104230). Western Region Climate Center, Reno, Nevada. <http://www.wrcc.dri.edu $>$. Accessed 25 Jan 2003.

Naylor, A. E., A. W. Miller, and M. E. Foster. 1954. Observations of the sandhill in northeastern California. Condor 56:224-227.

Rearden, J. D. 1951. Identification of waterfowl nest predators. Journal of Wildlife Management 15:386-395.

Rotella, J., S. J. Dinsmore, and T. L. Shaffer. 2005. Modeling nest-survival data: a comparison of recently developed methods that can be implemented in MARK and SAS. Animal Biodiversity and Conservation 27:187-205

SAS Institute. 2002. SAS OnlineDoc ${ }^{\circledR}$, Version 9.1. SAS Institute, Inc. Cary, North Carolina, USA.

Sargeant, A. B., and P. M. Arnold. 1984. Predator management for ducks on waterfowl production areas in the northern plains. Vertebrate Pest Conference 11:161-167.

Scheaffer, R. L., W. Mendenhall, and L. Ott. 1986. Elementary survey sampling. PWS-Kent, Boston, Massachusetts, USA.

Shaffer, T. L. 2004. A unified approach to analyzing nest success. Auk 121: 526-540.

Sharp, D. E., J. A. Dubovsky, R. E. Trost, E. M. Martin, J. W. Solberg, P. P. Thorpe, and R. C. Drewien. 2002. Status and harvests of the Midcontinent and Rocky Mountain populations of sandhill cranes, 2001. U.S. Fish and Wildlife Service, Denver, Colorado, USA.

Smith, E. B., and W. P. Smith. 1992. Environmental criteria for nest site selection by Mississippi sandhill cranes. Proceedings Annual Conference of Southeastern Association of Fish and Wildlife Agencies 42:431-442.

Steel, P. E. 1952. Factors affecting waterfowl production at Gray's Lake, Idaho. Thesis, University of Idaho, Moscow, USA.

Stern, M. A., G. J. Pampush, and R. E. Del Carlo. 1987. Nesting ecology and productivity of greater sandhill cranes at Sycan Marsh, Oregon. Pages 249-256 in J. C. Lewis, editor. Proceedings of the 1985 crane 
workshop. Platte River Whooping Crane Maintenance Trust, Grand Island, Nebraska, USA

Traylor, J. J., R. T. Alisauskas, and F. P. Kehoe. 2004. Nesting ecology of white-winged scoters (Melanitta fusca deglandi) at Redberry Lake, Saskatchewan. Auk 121:950-962.

Urbanek, R. P., and T. A. Bookhout. 1992. Nesting of greater sandhill cranes on Seney National Wildlife Refuge. Pages 161-167 in D. A.

Wood, editor. Proceedings of the 1988 North American crane workshop.
Florida Game and Fresh Water Fish Commission, Nongame Wildlife Program Technical Report 12, Tallahassee, USA.

Walkinshaw, L. H. 1973. Cranes of the world. Winchester Press, New York, New York, USA.

Westerkov, K. 1950. Methods for determining the age of game bird eggs. Journal of Wildlife Management 14:56-67.

Associate Editor: Hupp. 